DOI: $10.21767 / 2471-805 \times .100023$

\title{
Functional Movement Disorders: Updated Overview
}

\section{Abstract}

Functional movement disorders are relatively common neurological manifestations that are not related to a known neurological or a medical diagnosis. We aim to present an updated overview of this topic and present important diagnostic tips and pitfalls in the management of theses potentially puzzling presentations. Particularly, as such psychosomatic disorders could simulate known disorders, including tremor, paralysis, seizures, or ataxia. This often results in excessive, unnecessary and costly investigations, which may in turn further enhance the sick role and complicates the management. Early recognition and prompt intervention are needed to prevent social and academic disruptions, and hence a debilitating outcome.

Keywords: Functional; Movement; Disorders; Update; Review

Received: January 17, 2017; Accepted: January 27, 2017 ; Published: January 30, 2017

\section{Introduction}

Functional movement disorders (FMD) are relatively common neurological manifestations that are not related to a known neurological or a medical diagnosis including abnormal involuntary movements that can be affected by distraction or prompting [1-3]. Such psychosomatic disorders can take many forms and could simulate known disorders, including tremor, paralysis, seizures, or ataxia. If the proper diagnosis and management are not instituted promptly, they may become debilitating and results in significant social and academic disruptions [4]. It is important to note that these patients are not fabricating the signs and symptoms (malingering), despite of absence of an organic pathology. Functional movement disorders often result in excessive, unnecessary, and costly investigations, which may in turn further enhance the sick role and complicates the management [5].

\section{How common of a problem are FMD?}

FMD affect both adults and children. There is a relative shortage in pediatric data mainly the result of diagnostic difficulties [6]. The estimated pediatric prevalence ranges between 1-4 per 100,000 $[7,8]$. Motor weakness and abnormal movements were the most common symptoms among children [7]. In another study, pseudoseizures constitute $25 \%$ of children with FMD [9]. All ages are affected and patients as young as 4 years were identified $[10,11]$. Such cases often present repeatedly to pediatric

\author{
Ahmed H Subki, \\ Abdulaziz M Alkahtani, \\ Ahmed A Alfayez, \\ Rayan A Atoudi, \\ Mohammed A Rio, \\ Ibrahim M Alsheikh and \\ Mohammed M Jan
}

\begin{abstract}
Department of Pediatrics, Faculty of Medicine, King AbdulAziz University Hospital, Jeddah, Kingdom of Saudi Arabia
\end{abstract}

Corresponding author: Dr. Mohammed MS Jan

\section{mmjan@kau.edu.sa}

Department of Pediatrics, King Abdulaziz University Hospital, P O Box 80215, Jeddah 21589, Kingdom of Saudi Arabia.

Tel: 996-012-6401000 (ext. 20208)

Fax: 996-012-6403975

Citation: Subki AH, Alkahtani AM, Alfayez $A A$, et al. Functional Movement Disorders: Updated Overview. J Pediatr Care. 2017, 3:1.

neurology. In a study by the National Health Service, one third of 3781 patients who presented to neurology clinics had symptoms that were categorized as 'somewhat' or 'not at all' explained by organic disease [12]. A recent study from Saudi Arabia found up to $8 \%$ of referrals with psychiatric complaints were diagnosed as functional [13]. Such patients often have repeated emergency room visits or hospital admissions [14]. In general, FMD are more common in females with a 3-4:1 ratio among children aged 12-14 years [15-17].

\section{How can we explain the occurrence of FMD?}

Some studies suggested functional changes in the brain including reduced regional cerebral blood flow in the thalamus and basal ganglia contralateral to the involved region using single photon emission computerized tomography (SPECT) $[18,19]$. These changes were transient. Another study using electroencephalography (EEG) and functional magnetic resonance imaging (MRI) also showed abnormal changes [20- 
22]. These included increased dorsolateral prefrontal cortex activity, reduced hippocampal and para-hippocampal activity, increased activity in the right supplementary motor area, and temporoparietal junction. Other studies revealed decreased right inferior frontal cortex activity, and increased connectivity between the right supplementary motor area SMA and left amygdala [23,24]. Finally, a study using Voxel-based morphometry in hemiparetic motor conversion, increased cortical thickness in the bilateral premotor cortex and a trend towards increased grey matter volume were found [25]. Such data suggests that there are genuine changes, often transient, that occur in the brain as a result or in association with FMD.

\section{Clinical Spectrum}

FMD usually presents as a single movement disorder affecting the dominant extremities, however, complex movements or gait disorders are also common [26-28]. Children with functional disorders are expected to make a full recovery, as the conversion symptoms last no longer than 3 months typically [29]. The majority of them have a good long-term outcome with a rare recurrence of symptoms in general [30-32]. Triggering factors or precipitating events are often identified [33]. These include physical injury, infection, surgery, or other significant stressful life events [34]. Irritability, depressive mood, and anxiety often coexist among these children [35]. Others become anorexic with considerable weight loss [36].

\section{Aids in diagnosis}

Suggestion and placebo challenge can aid in distinguishing psychogenic from organic disease. Its use is controversial because it may affect the trust and doctor-patients relationship. However, when it is used as part of comprehensive treatment, it can play a role in the diagnosis [37]. Electrodiagnostic testing can provide additional supportive evidence for the diagnosis of FMD. Surface electromyography (EMG) for tremor analysis and accelerometry can identify features associated with functional tremor which include entrainment of tremor, simultaneous activity in agonists and antagonists muscles, increased tremor amplitude and frequency with weight loading of the involved limb and variability in tremor frequency $[38,39]$. However, diagnoses should not be made solely on frequency variability, as there is often an overlap between organic and functional tremor $[40,41]$. In contrast, a tremor occurring in different muscle groups at different frequencies or tremors faster than $11 \mathrm{~Hz}$ usually indicates an organic etiology [42]. Electrodiagnostic techniques can also be helpful in differentiating functional myoclonus from true myoclonus. Features associated with functional myoclonus on surface EMG include abnormally long and variable latency between the stimulus and the onset of movement; prolonged myoclonic burst duration with a well-organized triphasic pattern of agonist and antagonist muscle activation. In organic myoclonus, the myoclonic jerk has a short latency of less than 70 $\mathrm{ms}$. A pattern consistent with voluntary movement is suggestive of functional myoclonus [43].

\section{Diagnosis}

A careful understanding of the nature of FMDs is recommended for diagnostic accuracy. Due to an attributed similarity, it has been documented that some organic disorders have been mistaken for functional disorders in the past, examples of which are both Tourette's syndrome and task-specific focal dystonias. Thereby, an acknowledged proficiency of neuroanatomy and neurophysiology is in order and must be kept in mind to correctly interpret abnormal presentations of recognized diseases. For instance, organic disorders may present with some controlled movements such as tics, tardive dyskinesias, parkinsonian rest tremors and chorea. Others are characterized by an abrupt onset followed by remission [44]. Organic paroxysmal dyskinesias may be passed for a psychogenic etiology; however, the clinical features of functional paroxysmal movement disorders allow a differentiation [45]. On the other hand, it should also be noted that some diseases exhibiting movement disorders might initially present with psychiatric dysfunction, such as Huntington's disease and Wilson's disease. Although they are separate diseases, organic and functional movement disorders may coexist in some patients. This is also rarely seen in cases of epilepsy. In order to allow for further advancement in the accuracy of diagnosis, it has been suggested to follow the guidance of clinically based and phenotype-specific FMD diagnostic criteria. This will include the signs and symptoms from a clinical examination in addition to the findings from history taking. Many times an experienced neurologists with a specialized background on movement disorders is needed in order to make the diagnosis of FMD's clinically and not as a diagnosis of exclusion [46]. One incorrect notion, however popular, is that functional movement disorders are a diagnosis of exclusion when in fact obtaining a thorough personal, neurological, and family history as well as detailed examination is necessary to make the diagnosis (Table 1). In some cases, the need for diagnostic testing is needed [47].

\section{Clues to the diagnosis in specific types of FMD}

FMD can take the shape of known movement disorders, tremor being a most common presentation followed by dystonia, myoclonus, and ataxia [48]. Tics have been reported, along with other possible but less common movement disorders such as psychogenic Parkinsonism, psychogenic facial movements, some ocular manifestations, and palatal tremor. The following specific discussion will help differentiate the functional types:

Table 1 Aids in diagnosing FMD's in pediatric patients.

\begin{tabular}{|c|c|}
\hline History & $\begin{array}{l}\text { Sudden onset of symptoms, followed by a plateau } \\
\text { Subside if patient was unknowingly watched } \\
\text { Presence of secondary gain } \\
\text { Spontaneous remission }\end{array}$ \\
\hline \multirow{7}{*}{ Examination } & Variable nature of the movement \\
\hline & Increase by watching and if not, they decrease \\
\hline & Lack of anatomic or physiologic correlations \\
\hline & Continuous unremitting or out of proportion \\
\hline & Intervention to initiate or stop the movements \\
\hline & Entrainment \\
\hline & Deliberate slowness of the movement \\
\hline \multirow{3}{*}{$\begin{array}{l}\text { Therapeutic } \\
\text { outcomes }\end{array}$} & Improvement upon the use of placebo \\
\hline & Positive recovery after sessions of physiotherapy \\
\hline & Pertinent medications show no significant impact \\
\hline
\end{tabular}


Tremor: Variability in the tremor character was greater than $90 \%$, while amplitude and frequency variance was observed in all subjects, frequently males $[49,50]$. There may be some tonic co-activation at tremor onset. The tremors usually consisted of resting, postural, and kinetic components along with a selective but not task specific disabilities. It changes by distraction often pause during contralateral ballistic movements. Neurological examination was indecisive, and drug treatment was ineffective. A nice trick is to elicit an increase in tremor amplitude with weight loading. Children with psychogenic tremor may be more likely to be diagnosed with an FMD based on clinical grounds and without extensive laboratory or imaging investigations [51].

Dystonia: Features of organic dystonia are summarized in Table 2. Functional dystonis is often painful with associated non-anatomic sensory changes and false weakness [52]. Most patients have movements that are inconsistent with those of dystonia. Four distinctive functional dystonia phenotypes have been identified including; 1) fixed wrist and finger flexion often with relative sparing of the thumb and index fingers, 2) fixed foot plantar flexion and inversion, 3) unilateral lip and jaw deviation, and 4) torticollis with ipsilateral shoulder elevation and contralateral shoulder depression [41]. On the other hand, organic dystonia can be misdiagnosed as psychogenic due to the intermittent nature and variation in the presentation.

Myoclonus: The movements are typically segmental rather than focal or generalized in nature, occurring at rest and often exacerbated by voluntary movement [53]. It tends to be more common in females and when axial it is often flexion in character. The jerks occur in a non-stereotyped multifocal manner with no clear pattern.

Tics: These are trickier as tics are often triggered by emotional or psychological stress [54]. Tics in the setting of a psychogenic illness have a sudden dramatic onset of jerking movements usually involving one or both arms, head, and neck $[55,56]$. These tics are not preceded by premonitory urges, were not suppressible, and were not stereotyped. In addition, older age of onset and lack of family history should raise the suspicion even further. Thus, the movements differed from true tics in several important diagnostic features.

Ataxia: The presence of knee buckling or astasia-abasia alone suffices to confirm a diagnosis of primary functional gait disorder [57]. An alternative presentation includes an atypical or bizarre gait such as, tightrope walking, trembling, stiff-legged gait, dragging, scissoring gait, gradual fatigue, truncal myoclonic gait,

Table 2 Features suggestive of organic rather than functional intermittent dystonia [37].

\begin{tabular}{|c|}
\hline Writhing, jerking, spasms, and tremors \\
Spontaneous remission \\
Task-specificity or action induction \\
Normal neurological exam \\
Relief through sensory trick \\
\hline Worsening with stress and relief by relaxation \\
Paroxysmal appearance or diurnal variation
\end{tabular}

and walking-on-ice gait $[58,59]$. The need to include at least one associated FMD in gait patterns other than knee buckling and astasia-abasia should protect against the incorrect diagnosis of functional gait in patients with bizarre but organic gait disorders.

Chorea: The diagnosis of isolated functional chorea, the rarest of functional phenotypes, cannot be made with clinically definite certainty because the key features of variability in speed and amplitude, entrainment, suppressibility, and changes in distribution can be seen in organic chorea [60]. In modern series of FMD, psychogenic chorea and athetosis have a relatively low prevalence of less than $12 \%$ [61].

Psychogenic Parkinsonism: Psychogenic Parkinsonism has been reported in several studies [62,63]. Tremor and bradykinesia are the two most common features observed in patients with psychogenic Parkinsonism. Tremor usually has the same features as psychogenic tremor without Parkinsonism. Bradykinesia in psychogenic Parkinsonism patients is usually unaccompanied by amplitude decrement or interruptions in repetitive movements as observed in Parkinson disease (Table 3). Features of psychogenic gait such as buckling of the knees and astasia-abasia may be observed [64]. Arm swing can be reduced or abolished in psychogenic Parkinsonism, sometimes with one arm held stiffly extended and adducted to the side. This feature can persist while running.

Psychogenic facial movements: Psychogenic facial movements can present as lip protrusion, hemifacial spasm, or blepharospasm. The most common pattern of movements was lateral or downward lip protrusion with an ipsilateral deviation of the jaw. In contrast to organic oromandibular dystonia, patients had a unilateral involvement, and no sensory tricks or speech [65]. In psychogenic hemifacial spasm, an earlier age of onset was noted with no simultaneous compensatory contractions of the frontalis muscle and a normal blink reflex [66-68].

Ocular manifestations: Convergence spasm consisting of episodes of lens accommodation with ocular convergence usually causing diplopia is evoked mainly by horizontal ocular pursuit $[69,70]$. Rarely, functional upward gaze paralysis accompanies such convergence spasm.

Palatal tremor (palatal myoclonus): Palatal tremor (palatal myoclonus) is characterized by abnormal rhythmic contractions of palatal muscles (tensor veli palatini muscle). Voluntary control of palatal muscles seems necessary for the development of psychogenic palatal tremor [71]. Entrainment and distractibility of palatal movements in psychogenic patients are key features [72]. Patients with psychogenic palatal tremor were younger than patients with symptomatic palatal tremor, more frequently female, had a history of a precipitating event, and frequently complain of ear clicking and multiple somatizations [73].

\section{Misdiagnosis}

In general, physicians are hesitant to make the diagnosis of FMD resulting in significant diagnostic and management delays. Pediatric patients have reportedly undergone uncalled for investigations and treatments without benefit. Precise 
Table 3 Difference between psychogenic Parkinsonism and Parkinson's disease.

\begin{tabular}{|c|c|c|}
\hline & Psychogenic Parkinsonism & Parkinson's disease \\
\hline Onset & Sudden onset, maximal deficit soon after & Insidious onset \\
\hline Course & $\begin{array}{l}\text { Non-progressive course with fluctuating, } \\
\text { transient or permanent remission }\end{array}$ & Progressive evolution \\
\hline Rigidity & $\begin{array}{l}\text { Active resistance to passive movements on } \\
\text { examination (paratonia). Absent cogwheel } \\
\text { phenomena }\end{array}$ & Cogwheel phenomena \\
\hline Effect of distraction & Decrease in amplitude or disappear & Increase in amplitude \\
\hline Effect of reinforcement & Rigidity diminishes & Rigidity diminishes \\
\hline Freezing & Absent & Common \\
\hline Arm posture while walking & $\begin{array}{l}\text { Extended in adduction, held stiffly at side (this } \\
\text { posture may persist while running) }\end{array}$ & Partially flexed \\
\hline Tremor & Rest, postural, kinetic & Rest, postural, kinetic \\
\hline Bradykinesia (repetitive movement) & Slowness without amplitude decrement & Progressive slowness with amplitude decrement \\
\hline
\end{tabular}

diagnosis is of crucial significance to avoid such unnecessary delay. Identifying pitfalls associated with each diagnostic criterion may be one step forward towards achieving a definitive diagnosis. Any movement disorder that does not pose irregular organic manifestations, may be falsely interpreted, as a clinically definitive FMD should the presence of pain, exposure to a disease model, potential for secondary gain, and multiple somatizations is verified [74].

\section{Management and Outcome}

These patients need a multidisciplinary treatment plan that includes the cooperation of both the neurologist and the patient to get a better outcome. Since the patients have difficulty in accepting the idea of psychogenic origin disorder, they prefer the term "Functional" movement disorders [75]. The diagnosis is followed by the treatment of the disorder, with no further testing. Evaluations by different specialties are recommended to determine the precipitating factors important in designing the treatment plan. Supportive treatments include physical therapy, psychotherapy, physical exercise, and self-relaxation techniques [76-80]. Occasionally, antidepressants are used in patients with depressive symptoms [81,82]. Despite all interventions, some patients continue to have symptoms [83]. Better outcome is noted in those with more acute problems, with symptoms of shorter duration, with an identifiable stressor, and in those who lack a coexisting organic psychopathology [84-86]. 


\section{References}

1 Edwards MJ, Fotopoulou A, Parees I (2013) Neurobiology of functional (psychogenic) movement disorders. Curr Opin Neurol. 26: 442-447.

2 Head $\mathrm{H}$ (1922) An address on the diagnosis of hysteria Br Med J. 1: 827-829.

3 Charcot JM, Goetz CG (1887) Charcot the Clinician. The tuesday lessons. Excerpts from nine case presentations on general neurology delivered at the Salpêtrière Hospital in 2: 881-989.

4 Bidaki R, Zarepur E, Akrami M, Mohammad M (2016) Functional neurological symptom disorder: Mismanagement, misdiagnosis, chronic cough following sexual abuse: A rare case report. Iran J Child Neurol 10(2): 90-92.

5 Gupta A, Lang AE (2009) Psychogenic movement disorders. Curr Opin Neurol. 22: 430-436.

6 Sheffield $\mathrm{H}$ (1898) A contribution to the study of hysteria in childhood as it occurs in the United States of America. NY State J Med. 68: 412-416.

7 Ani C, Reading R, Lynn R, Forlee S, Garralda E (2013) Incidence and 12-month outcome of non-transient childhood conversion disorder in the U.K. and Ireland. Br J Psychiatry. 202: 413-418.

8 Kozlowska K, Nunn KP, Rose D, Morris A, Ouvrier RA, et al. (2007) Conversion disorder in Australian pediatric practice. J Am Acad Child Adolesc Psychiatry. 46: 68-75.

9 Khan F AT, Bhimani M, Zaman M, Nadeem T (2014) Pattern of child psychiatric emergencies and consults in a tertiary care hospital, Karachi. Journal of Pakistan Psychiatric Society.

10 Williams DT, Ford B, Fahn S (1995) Phenomenology and psychopathology related to psychogenic movement disorders. Adv Neurol. 65: 231-257.

11 Putnam F, Joseph A, Young R (1992) Movement disorders in neurology and neuropsychiatry Boston: Blackwell Scientific Publications. 1992: 430-437.

12 Stone J, Carson A, Duncan R, Coleman R, Roberts R, et al. (2009) Symptoms 'unexplained by organic disease in 1144 new neurology out-patients: How often does the diagnosis change at follow-up? Brain.

13 Chaleby K (1995) A survey of a child psychiatry clinic in a teaching hospital in Saudi Arabia. Saudi Med J.

14 Merkler AE, Parikh NS, Chaudhry S, Chait A, Allen NC, et al. (2016) Hospital revisit rate after a diagnosis of conversion disorder. J Neurol Neurosurg Psychiatry. 87: 363-366.

15 Dale RC, Singh H, Troedson C, Pillai S, Gaikiwari S, et al. (2010) A prospective study of acute movement disorders in children. Dev Med Child Neurol. 52: 739-748.

16 Fernandez-Alvarez E (2005) Movement disorders of functional origin (psychogenic) in children. Rev Neurol. 40 Suppl 1: S75-S77.

17 Ferrara J, Jankovic J (2008) Psychogenic movement disorders in children. Mov Disord. 23: 1875-1881.

18 Balaratnasingam S, Janca A (2006) Mass hysteria revisited. Current Opinion in Psychiatry 19: 171-174.

19 Vuilleumier P, Chicherio C, Assal F, Schwartz S, Slosman D, et al. (2001) Functional neuroanatomical correlates of hysterical sensorimotor loss. Brain 124: 1077-1090.
20 Edwards MJ, Fotopoulou A, Parees I (2013) Neurobiology of functional (psychogenic) movement disorders. Current opinion in neurology 26: 442.

21 Labate A, Cerasa A, Mula M, Mumoli L, Gioia MC, et al. (2012) Neuroanatomic correlates of psychogenic nonepileptic seizures: $A$ cortical thickness and VBM study. Epilepsia. 53: 377-385.

22 Vuilleumier P (2005) Hysterical conversion and brain function. Prog Brain Res. 150: 309-329.

23 Aybek S, Nicholson TR, Zelaya F, O'Daly OG, Craig TJ, et al. (2014) Neural correlates of recall of life events in conversion disorder. JAMA psychiatry. 71: 52-60.

24 Voon V, Brezing C, Gallea C, Ameli R, Roelofs K, et al. (2010) Emotional stimuli and motor conversion disorder. Brain.

25 Aybek S, Nicholson TR, Draganski B, Daly E, Murphy DG, et al. (2014) Grey matter changes in motor conversion disorder. J Neurol Neurosurg Psychiatry. 85: 236-238.

26 Canavese C, Ciano C, Zibordi F, Zorzi G, Cavallera V, et al. (2012) Phenomenology of psychogenic movement disorders in children. Mov Disord. 27: 1153-1157.

27 Regan J, LaBarbera JD (1984) Lateralization of conversion symptoms in children and adolescents. Am J Psychiatry. 141: 1279-1280.

28 Schwingenschuh P, Pont-Sunyer C, Surtees R, Edwards MJ, Bhatia KP (2008) Psychogenic movement disorders in children: a report of 15 cases and a review of the literature. Mov Disord. 23: 1882-1888.

29 Fritz GK, Fritsch S, Hagino O (1997) Somatoform disorders in children and adolescents: a review of the past 10 years. J Am Acad Child Adolesc Psychiatry. 36: 1329-1338.

30 Turgay A (1990) Treatment outcome for children and adolescents with conversion disorder. Can J Psychiatry. 35: 585-589.

31 Grattan-Smith P, Fairley M, Procopis P (1988) Clinical features of conversion disorder. Arch Dis Child. 63: 408-414.

32 Ahmed MA, Martinez A, Yee A, Cahill D, Besag FM (2008) Psychogenic and organic movement disorders in children. Dev Med Child Neurol. 50: $300-304$.

33 Zeharia A, Mukamel M, Carel C, Weitz R, Danziger Y, et al. (1999) Conversion reaction: Management by the paediatrician. Eur J Pediatr. 158: $160-164$

34 Eminson M (2001) Somatising in children and adolescents: Clinical presentations and aetiological factors. Advances in Psychiatric Treatment. 7: 266-274.

35 Association AP (2013) Diagnostic and Statistical Manual of Mental Disorders, (5thedn): DSM-5. Arlington, TX: American Psychiatric Association.

36 Kozlowska K (2001) Good children presenting with conversion disorder. Clin Child Psychol Psychiatry. 2001: 575-591.

37 Fahn S, Williams DT (1988) Psychogenic dystonia. Adv Neurol. 50: 431-455.

38 Schwingenschuh P, Saifee TA, Katschnig-Winter P, Macerollo A, KoeglWallner M, et al. (2016) Validation of "laboratory-supported" criteria for functional (psychogenic) tremor. Mov Disord. 31: 555-562.

39 Deuschl G, Koster B, Lucking CH, Scheidt C (1998) Diagnostic and pathophysiological aspects of psychogenic tremors. Mov Disord. 13: 294-302.

40 McAuley JH, Rothwell JC, Marsden CD, Findley LJ (1998) 
Electrophysiological aids in distinguishing organic from psychogenic tremor. Neurology. 50: 1882-1884.

41 Schwingenschuh P, Katschnig P, Seiler S, Saifee TA, Aguirregomozcorta $M$, et al. (2011) Moving toward "laboratory-supported" criteria for psychogenic tremor. Mov Disord. 26: 2509-2515.

42 Brown P, Thompson PD (2001) Electrophysiological aids to the diagnosis of psychogenic jerks, spasms, and tremor. Mov Disord. 16: 595-599.

43 Thompson PD, Colebatch JG, Brown P, Rothwell JC, Day BL, et al. (1992) Voluntary stimulus-sensitive jerks and jumps mimicking myoclonus or pathological startle syndromes. Mov Disord. 7: 257-262.

44 Brashear A, Dobyns WB, De Carvalho Aguiar P, Borg M, Frijns CJ, et al. (2007) The phenotypic spectrum of rapid-onset dystoniaparkinsonism (RDP) and mutations in the ATP1A3 gene. Brain. 130: 828-835.

45 Ganos C, Aguirregomozcorta M, Batla A, Stamelou M, Schwingenschuh $P$, et al. (2014) Psychogenic paroxysmal movement disorders--clinical features and diagnostic clues. Parkinsonism Relat Disord. 20: 41-46.

46 Espay AJ, Lang AE (2015) Phenotype-specific diagnosis of functional (psychogenic) movement disorders. Curr Neurol Neurosci Rep. 15: 32.

47 Kirsch DB, Mink JW (2004) Psychogenic movement disorders in children. Pediatr Neurol. 30: 1-6.

48 Factor SA, Podskalny GD, Molho ES (1995) Psychogenic movement disorders: frequency, clinical profile, and characteristics. J Neurol Neurosurg Psychiatry. 59: 406-412.

49 Koller W, Lang A, Vetere-Overfield B, Findley L, Cleeves L, et al. (1989) Psychogenic tremors. Neurology. 39: 1094-1099.

50 Thenganatt MA, Jankovic J (2014) Psychogenic tremor: A video guide to its distinguishing features. Tremor Other Hyperkinet Mov (NY). 4: 253.

51 Kenney C, Diamond A, Mejia N, Davidson A, Hunter C, et al. (2007) Distinguishing psychogenic and essential tremor. J Neurol Sci. 263: 94-99.

52 Lang AE (1995) Psychogenic dystonia: A review of 18 cases. Canadian Journal of Neurological Sciences/Journal Canadien des Sciences Neurologiques 22: 136-143.

53 Erro R, Edwards MJ, Bhatia KP, Esposito M, Farmer SF, et al. (2014) Psychogenic axial myoclonus: clinical features and long-term outcome. Parkinsonism Relat Disord. 20: 596-599.

54 Baizabal-Carvallo JF, Jankovic J (2013) The clinical features of psychogenic movement disorders resembling tics. J Neurol Neurosurg Psychiatry.

55 McVige J, Fritz C, Mechtler L (2012) Mass psychogenic illness in Leroy High School, New York. Ann Neurol: Wiley-Blackwell 111 River ST, Hoboken 07030-5774, NJ USA.

56 Mink JW (2013) Conversion disorder and mass psychogenic illness in child neurology. Ann N Y Acad Sci. 1304: 40-44.

57 Morgante F, Edwards MJ, Espay AJ (2013) Psychogenic movement disorders. CONTINUUM: Lifelong Learning in Neurology. 19: 13831396.

58 Gupta A, Lang AE (2009) Psychogenic movement disorders. Current Opinion in Neurology 22: 430-436.

59 Van Der Salm SM, De Haan RJ, Cath DC, Van Rootselaar AF, Tijssen MA (2013) The eye of the beholder: inter-rater agreement among experts on psychogenic jerky movement disorders. J Neurol
Neurosurg Psychiatry. 84: 742-747.

60 Micheli F, Le-Witt P (2014) Psychogenic chorea. In: Chorea: Causes and Management. London: Springer p. 356-361.

61 Thomas M, Jankovic J (2004) Psychogenic movement disorders: diagnosis and management. CNS Drugs. 18: 437-452.

62 Lang AE, Koller WC, Fahn S (1995) Psychogenic parkinsonism. Arch Neurol. 52: 802-810.

63 Jankovic J (2011) Diagnosis and treatment of psychogenic parkinsonism. J Neurol Neurosurg Psychiatry. 82: 1300-1303.

64 Hallett M (2011) Psychogenic parkinsonism. J Neurol Sci. 310: 163-165.

65 Fasano A, Valadas A, Bhatia KP, Prashanth L, Lang AE, et al. (2012) Psychogenic facial movement disorders: clinical features and associated conditions. Mov Disord. 27: 1544-1551.

66 Yaltho TC, Jankovic J (2011) The many faces of hemifacial spasm: Differential diagnosis of unilateral facial spasms. Mov Disord. 26: 1582-1592.

67 Stamey W, Jankovic J (2007) The other Babinski sign in hemifacial spasm. Neurology 69: 402-404.

68 Schwingenschuh $\mathrm{P}$, Katschnig $\mathrm{P}$, Edwards M, Teo J, Korlipara L, et al. (2011) The blink reflex recovery cycle differs between essential and presumed psychogenic blepharospasm. Neurology. 76: 610-614.

69 Fekete R, Baizabal-Carvallo JF, Ha AD, Davidson A, Jankovic J (2012) Convergence spasm in conversion disorders: prevalence in psychogenic and other movement disorders compared with controls. J Neurol Neurosurg Psychiatry. 83: 202-204.

70 Ghosh A, Padhy SK, Gupta G, Goyal MK (2014) Functional convergence spasm. Indian J Psychol Med. 36: 332.

71 Klein C, Gehrking E, Vieregge P (1998) Voluntary palatal tremor in two siblings. Mov Disord. 13: 545-548.

72 Samuel M, Kleiner-Fisman G, Lang AE (2004) Voluntary control and a wider clinical spectrum of essential palatal tremor. Mov Disord. 19: 717-719.

73 Stamelou M, Saifee TA, Edwards MJ, Bhatia KP (2012) Psychogenic palatal tremor may be underrecognized: reappraisal of a large series of cases. Mov Disord. 27: 1164-1168.

74 Shill H, Gerber P (2006) Evaluation of clinical diagnostic criteria for psychogenic movement disorders. Mov Disord. 21: 1163-1168.

75 Edwards MJ, Stone J, Lang AE (2014) From psychogenic movement disorder to functional movement disorder: it's time to change the name. Mov Disord. 29: 849-852.

76 Czarnecki K, Thompson JM, Seime R, Geda YE, Duffy JR, et al. (2012) Functional movement disorders: successful treatment with a physical therapy rehabilitation protocol. Parkinsonism Relat Disord. 18: $247-251$

77 Goldstein LH, Chalder T, Chigwedere C, Khondoker MR, Moriarty J, et al. (2010) Cognitive-behavioral therapy for psychogenic nonepileptic seizures: A pilot RCT. Neurology. 74: 1986-1994.

78 Dallocchio C, Arbasino C, Klersy C, Marchioni E (2010) The effects of physical activity on psychogenic movement disorders. Mov Disord. 25: 421-425.

79 Garcin B, Roze E, Mesrati F, Cognat E, Fournier E, et al. (2013) Transcranial magnetic stimulation as an efficient treatment for psychogenic movement disorders. J Neurol Neurosurg Psychiatry. 84: 1043-1046. 
80 Moene FC, Spinhoven P, Hoogduin KA, Van Dyck R (2003) A randomized controlled clinical trial of a hypnosis-based treatment for patients with conversion disorder, motor type. Int J Clin Exp Hypn. 51: 29-50.

81 Ricciardi L, Edwards MJ (2014) Treatment of functional (psychogenic) movement disorders. Neurotherapeutics. 11: 201-207.

82 Hallett M (2010) Physiology of psychogenic movement disorders. J Clin Neurosci. 17: 959-965.

83 Feinstein A, Stergiopoulos V, Fine J, Lang AE (2001) Psychiatric outcome in patients with a psychogenic movement disorder: A prospective study. Neuropsychiatry Neuropsychol Behav Neurol. 14: 169-176.

84 Thomas M, Vuong KD, Jankovic J (2006) Long-term prognosis of patients with psychogenic movement disorders. Parkinsonism Relat Disord. 12: 382-387.

85 Gelauff J, Stone J, Edwards M, Carson A (2014) The prognosis of functional (psychogenic) motor symptoms: a systematic review. J Neurol Neurosurg Psychiatry. 85: 220-226. 